\title{
Study on the Use of Chinese Advertising English and Its Translation Techniques
}

\author{
Jing Xiang*, Jing Chu \\ College of Literature, Bohai University, Jinzhou, Liaoning, 121013, China \\ *Correspondence Author, jxheung @foxmail.com
}

\begin{abstract}
Nowadays, with the globalization of world economy, knowing how to use advertising English in opening up overseas markets is of very practical significance. The purpose of advertising is to promote business sales and services, which creates added value in customer's mind and lead to consumption, usually paid for by related sponsors through various media. Taking Coca-Cola for example, during its growth over a century, it has been supporting the advertising campaign in one stage after another, and in one country after another. Therein, 可口可乐, the Chinese translation soon became a household name in China, and it also played an important role in helping Coca-Cola tap into Chinese market. Admittedly, the competitive quality of product itself is important, but advertising is of much more importance to promote itself to be recognized worldwide. In translation, its techniques should be taken into account, which will help us to better use advertising English. It is true that good translation in advertising brings business great fortune, whereas bad one may result in severe losses and poor reputation, so we can see advertising translation is bound up with enterprise's prosperity and decline. Therefore, the use of advertising English and its translation techniques should be valued. In this paper, the writer is doing study on the use of advertising English and its translation techniques, whereby current research situation of that in China and abroad, factual methodologies and related materials have all contributed to its completion. The writer believes that both one's ability of ingenious thinking and the growth of economic globalization are benefiting from a better use of advertising English and its translation techniques.
\end{abstract}

Keywords: Chinese, Advertising English, Translation techniques.

\section{Introduction}

\subsection{Research Background}

Since the dawn of mass media, newspaper, radio and television have all been used to inform the public. Accordingly, a variety of advertisements have emerged around the world since then, which have vastly accelerated globalization of world economy. In face of the ongoing economic globalization, for those enterprises involved, they are taking responsibility for their own prospect, to survive and thrive in the world market by advertising themselves. In fact, there is no surprise that most of the world's top companies have their own advertising slogans, which enabled them to be recognized worldwide. However, as a special practical style, advertising English and its translation have unique or ingenious ways of expressing and transmitting what needs to be informed to the public. But, the ways are sort of complex wordplay, poses a challenge to the use of advertising English and its translation techniques.

In conclusion, it is of great importance to make a further study on this topic.

\subsection{Purpose and Significance}

The world economy is ever-changing, there has been the rule of winning in the cruel business environment: survival of the fittest. That is, the law of nature works equally on commercial competition. Thereupon, advertising is one critical way out of isolation from the society of economic globalization. In this article, the writer of the thesis is trying to help readers to get to a better use of advertising English and its translation techniques.
Consequently, with a better use of advertising English and its translation techniques, it will develop one's ability of ingenious thinking, and it will be highly conducive to the growth of economic globalization.

\section{Literature Review}

2.1 The Definition of Advertising English and Its Translation

Advertising English, is the communication of information, especially in business sales and services, is designed to lead to targeted people informed and motivated, as a special practical style in an English environment. And its translation, in this paper, is based on the analysis between English and Chinese. Moreover, the advertising English and its translation is interconnected, a better use of advertising English constitutes the premise of a better use of its translation techniques.

\subsection{Current Research Situation of Advertising English and Its Translation in China}

In China, advertising English is playing an increasingly important role in our social economy, and it is becoming a research subject in a growing number of colleges and universities. Since made CCTV National Brand Plan in 2016, advertising English has been improving in China. At present, there are still problems lies in the use of advertising English, whether in quality or in quantity. It was found through investigation that non-native and even wrong advertising slogans are very common in shops, gardens, squares, and so on. Many existing problems in every aspect of making a successful advertising should be considered, including wording, style, culture, aesthetics, etc. After all, public and other related institutions have not attached much importance 
to advertising English and its translation. However, the importance of advertising English and its translation to enhancement of China's international competitiveness is not allowed to be overlooked, especially in such a world of economic globalization.

\subsection{Current Research Situation of Advertising English and Its Translation Abroad}

Advertising has roots in the Western developed countries with market economy, as a special practical style, it has been turned into an independent discipline in local educational institutions. What's more, it was established as a compulsory course in schools of business, and as a selective course in other schools, the related books and treatises are emerging one after another. According to the authoritative website's statistical data in recent years, the advertising expenditure in English-speaking countries accounts for more than a third of the world's top ten advertising spending markets. Hence, it follows that advertising English is of very importance to open up overseas markets.

\section{Methodology}

\subsection{Influence Factors in Using Advertising English}

\subsubsection{Cultural Nature}

As the carrier of culture, from side to side, advertising English reflected the social and cultural background, people's values and lifestyles in English-speaking countries. In other words, advertising English is based on its own cultural nature.

In English-speaking countries, holidays and festivals are very important to the people and are also the embodiment of national culture. Meanwhile, they are golden times for advertisers to take an active part in the advertising campaigns. In consideration of their own particular customs, there will be a mass of tailor-made advertisements springing up.

3.1.2 Aesthetic Sense

It is well known that all nationalities have their own unique taste in many aspects, with due respect for that, advertisers will be glad to take good reputation and favorable effects it will bring. For instance, Chinese people have a preference for red color and regard it as a symbol of celebration, presents are often covered with red packages. But in some African countries, red is less welcome. In addition, green color is disliked by Japanese, but popular in India. Therefore, aesthetic sense has a significant impact on the publishing of advertisements.

\subsection{Major Methods in Using Advertising English}

\subsubsection{Question Headline}

In advertising headline, it is obvious that flat words are less attractive than questioning ones, which is due to one's natural curiosity, one often eager to figure out something unknown but attractive. Following is a real example about the first iPad from the Apple Company in 2010: What is iPad? This is very brief, but powerful and inspiring in encouraging people to find out what it really is and even pay for it. On the contrary, there will be no room for people to satisfy their curiosity if it is told with flat words. In the same way, the automobile giant TOYOTA once had this slogan: Did you ever have the feeling you were followed? This is from the period when TOYOTA have the leading place in the development of environmental vehicle technology. TOYOTA's competitors are being asked if they are being able to reach this developing level it had reached, which makes itself stand out from the peers. Subsequently, a good reputation and a great number of orders will come together.

\subsubsection{Imperative Mood}

The purpose of advertising is to guide targeted people to agree on what it conveys, so the imperative mood is employed in a variety of advertisements. With an appropriate use of imperative mood, advertising language can give people a confident and convincing impression. Here is one classic example: Just do it. This is from Nike, the top sportswear brand in the world, which conveys its sportsmanship that encourage young people to make constant breakthrough. Meanwhile, it's never an old idea to promote its sport products. To a large extent, people are willing to choose Nike's products just because they're convinced of such a potent slogan. Here is another classic advertising slogan from the famous beverage brand Pepsi, Have a Pepsi day! Accordingly, people are likely to associate that expression with the daily greeting words: Have a good day! Virtually, people are encouraged to pay for its products with regarding it as a normal thing.

\subsubsection{Emphasis on Interests}

It is truth that most people are concerned about the interests of the products they may pay for, their choices depend largely on what interests will bring to them. Advertising slogans with much emphasis on interests, they are tend to be concise and comprehensive, instant and informative. Here comes a typical example: Grace space pace, which is from the luxury car brand Jaguar. These three words are briefly showing its three remarkable features, to the point where most people will concern. Likewise, the famous motorcycle brand Harley Davidson gives another example: American by Birth. Rebel by Choice. Liberty and rebellion are reflected in these words, which are the values rest in the people who are wild about the fast and the furious in the liberal America. It's often said that people are willing to make like-minded friends, it also works on buying and selling.

\subsubsection{Imitation on Maxims}

A maxim, by definition, is a well-known phrase or saying, especially one that gives advice or a rule for sensible behavior. With imitation on maxims, advertising English are far more interesting and attractive to the people. From the notable computer company IBM, I think, therefore IBM. It is a switch expression from the great philosopher and mathematician 
Descartes's saying: I think, therefore I am. In the saying, he explained the real value comes from rational thinking. For IBM's computers, they are trying to explain their fast computing power or logical capability that lies in the rational value. Another maxim goes: Where there is a will, there is a way. It tells people that there can be no more setbacks if they have the will to make achievements, and it is followed by a similar saying: Where there is a way for car there is a Toyota. The famous car brand TOYOTA is conveying the confidence in excellent performance its cars had.

\subsubsection{Rhetorical Devices}

Rhetoric is the art of speaking or writing to persuade or influence people, its main devices were used in advertising English, including exaggeration, personification, pun. First, exaggeration is a representation of something in an excessive manner by intensifying the effect of expression. Here is an example: Take the Toshiba, take the world. The successful company Toshiba is taking the leading place in the electronics industry, which is exaggerated to highlight its dominating force. Second, personification is to make the relevant things are endowed with life and emotion, it creates a kind impression and a considering feeling to people. The upmarket watch brand Rolex gives a good example, Unlike me, my Rolex never needs a rest. It just like the watch wearer is talking to himself or herself, which builds an emotional connection between the individual and the watch. More importantly, the watch's excellent quality is reflected in it. Third, pun is a clever use of a word or phrase that has two meanings, or of words that have the same sound but different meanings. The use of pun in advertising English will add enjoyment and humor to the targeted people, so as to let them willingly accept the commercial information it conveys. Here is a highly representative example from the world-renowned newspaper Times, Make time for times. It puns on the meaning of time, literally, it suggests people sparing time to read the newspaper Times in an artful manner.

\subsection{Methodical Use of Translation Techniques in Advertising English}

\subsubsection{Influence Factors in Translation of Advertising English}

Diverse cultural backgrounds, customs, and values are influence factors that exist in different nations, in which the people may have various opinions in one same advertising slogan. In other words, one product may be saleable in domestic market, but it will lead to poor sales when its advertising translation swerves from the customers' values in external markets. Therefore, it is of great importance to consider these factors mentioned above, they are necessary factors in making a good translation of advertising English.

\subsubsection{Literal Translation}

In the advertising translation process, literal translation makes the target and the source texts equivalent in form, content, and functions. Literal translation should be concerned when the source texts have a simple and complete structure, clear meaning. Typical examples are shown below:

\section{Challenge the limits to 挑战极限 \\ Obey your thirst to 服从你的渴望 \\ The taste is great to 味道好极了}

\subsubsection{Paraphrase}

Due to the difference of culture and language between English and Chinese, literal translation is restricted to convey the underlying or deeper meaning. However, paraphrase is a good way to it, which only follows the original content without regard to the form. This method is relatively flexible and free, translators can make some proper innovations with basic information unchanged, thus leading to a more acceptable advertising translation for customers. Following is a good example:

Can't beat the real thing to 抵挡不住的诱惑 This one is from the beverage giant Coca-Cola, the phrase the real thing in the text which has the original meaning of something that is authentic, and it refers to 正宗货 in Chinese, but the translator uses the Chinese phrase 诱惑 to denote the Coca-Cola's products, instead of using 正宗货 by indicating the products are irresistible, but not just authentic.

\subsubsection{Transliteration}

Transliteration, by definition, it means to convert words from one language to another language with a close approximation in phonetic sound. With a proper use of this method, a good advertising translation can be made. Following are some convincing examples:

The household name 可口可乐 is the translation to the beverage brand Coca-Cola. In Chinese, the word 可口 means something that is tasty, and 可乐 means something that is delightful, both are good words in Chinese and accord with the transliteration. Here is another example: Bens to 奔驰, this is from the leading automobile brand Bens, the Chinese translation precisely expresses a good image of its cars' speed.

\subsubsection{Structure Borrowing}

In advertising translation, a full understanding always comes first, otherwise there will be some wrong expressions. In fact, there is a phenomenon that many existing idioms, proverbs used for reference in advertising English to achieve the expected results, which is called structure borrowing. In its translation should follow the structure borrowing, to make the target and source texts consistent in meaning, thus conveying the connotation of the source texts. Here it comes some good examples:

We take no pride in prejudice is from the famous newspaper Times, and the Chinese translation is 对于您的偏见, 我们 没有傲慢, which shows the attitude of customer first, by 
borrowing the titles from the famous novel Pride and Prejudice, and its Chinese translation also followed its connotation. Another example goes: 不同凡想 to Think different, it's from the technology giant Apple. It is interesting to note that the word different should be replaced with differently in grammatical structure, but deliberately use this irregular structure to indicate that the people's way of thinking may be unchangeable, but the content of thinking should be different. It's also interesting that the Chinese translation 不同凡想 is followed by a classic Chinese idiom 不同凡响, which refers to something that is outstanding and distinctive. Likewise, the connotation of the phrase think different is conveyed by its Chinese translation 不同凡想.

\section{Conclusions}

Advertising English, as a special style in language, it has become an indispensable part in daily life. It's a good way to learn the culture and values in English-speaking countries, and to help enterprises exploit overseas market, getting by a better use of advertising English. For English majors, with a better use of advertising English, they can seize the pulse of the English development, and keep pace with the speed of the language development, thus contributing to an ever-improving level of English comprehension and appreciation.

The translation of advertising English, as a cross-cultural communication activity, which not only needs much practice but also guiding theoretical methods, it follows the features of high efficiency and functional equivalence. Moreover, its acceptance always comes first, and the conveying information is based on the reader's cognitive psychology. In addition, due to the difference of culture and language, the advertising translation is still a complex problem that needs continuous study. Therefore, the use of advertising translation techniques should be valued, which helps one develop an ingenious way of thinking, and makes contributions to the world of economic globalization.

\section{References}

[1] Liu Jichun. Translation: a Practical Course[M]. Guangzhou: Sun Yat-sen University Press, 2007(8): 237-238.

[2] Zhao Guangfa, Hu Yaling, Xue Yingying. Study on the Translation Theory and Practice of English Pragmatic Styles[M]. Beijing: China Water\&Power Press, 2016(9): 191-213.

[3] Xu Xiaojuan. Advertising English[M]. Beijing: Capital University of Economics and Business Press, 2013(7): 21-22.

[4] Cao Minglun. Translation: Application and Critique[M]. Chengdu: Sichuan People's Publishing House, 2007(5): 117-123.

[5] Weng Fengxiang. Contemporary International Business English Translation[M]. Shanghai: Shanghai Jiaotong University Press, 2007: 166-170.
[6] Li Yang, Luo Li, Li Lihua. Practical English-Chinese Translation[M]. Tianjin: Tianjin University Press, 2016(8): 64-71.

[7] Liu Xiuyu. A New Concise Handbook of English Advertising Writing[M]. Beijing: Encyclopedia of China Publishing House, 2002(5): 54-63. 